\section{Outdoor Home Gardener Preferences for Environmental Attributes in Gardening Supplies and Use of Ecofriendly Gardening Practices}

\author{
McKenzie Thomas ${ }^{1}$, Kimberly Jensen ${ }^{1}$, Margarita Velandia ${ }^{1}$, \\ Christopher Clark ${ }^{1}$, Burton English ${ }^{1}$, Dayton Lambert ${ }^{2}$, \\ and Forbes Walker ${ }^{3}$
}

\begin{abstract}
Additional INDEX words. attitudes, consumer, MIMIC, multiple indicatormultiple causes

SUMMARY. Home gardeners' concerns for the environment are expressed both in the ecofriendly gardening practices they use and in environmental attributes they prefer in the gardening products they purchase. This study uses data from a 2018 survey of 601 Tennessee outdoor home gardeners and a multiple indicators multiple causes (MIMIC) model to illustrate how outdoor home gardener demographics, expenditures, information use, and attitudes influence use of ecofriendly gardening practices and preferences for environmental attributes in home gardening supplies. Practices considered include planting pollinator plants, using rainwater collectors, composting, recycling gardening supplies packaging, using organic gardening methods, and use of soil testing. Gardening supply product attributes include decreased need for fertilizer, pesticides, and water; native plant species; organically produced products; and recyclable packaging. The most widely used practice is recycling gardening supplies packaging, and the least used is soil testing. Gardeners with a greater propensity to use the six gardening practices include male, college graduates, who spend relatively more of their income on gardening supplies, and consider themselves as being knowledgeable about environmental issues. The gardening supply product attribute most widely considered as important is decreased need for pesticides, and least widely considered as important are native species and organically produced. Gardeners more likely to prefer the six gardening supply product attributes include older gardeners, who seek other gardeners for information, and who perceived themselves as being knowledgeable about the environment. This same group likes to grow their own food and feels responsibility for protecting the environment for future generations.
\end{abstract}

$\mathrm{E}$ nvironmentally concerned gardeners may try to address larger environmental issues by using

Received for publication 10 June 2020. Accepted for publication 14 July 2020.

Published online 11 August 2020.

${ }^{1}$ Department of Agricultural and Resource Economics, the University of Tennessee, 2621 Morgan Circle, 302 Morgan Hall, Knoxville, TN 37996-4518

${ }^{2}$ Department of Agricultural Economics, 411 Agricultural Hall, Stillwater OK 74078-6026

${ }^{3}$ Department of Biosystems Engineering and Soil Sciences, the University of Tennessee, 2506 E.J. Chapman Drive, Knoxville, TN 37996-4531

This work was funded in part by the US Federal Aviation Administration (FAA) Office of Environment and Energy as a part of ASCENT Project 1 under FAA Award Number: 13-C-AJFEUTENN-Amd 5. Funding also was provided by the U.S. Department of Agriculture through Hatch Project TN000444. Any opinions, findings, and conclusions or recommendations expressed in this material are those of the authors and do not necessarily reflect the views of the FAA or other ASCENT sponsor organizations.

K.J. is the corresponding author. E-mail: kjensen@utk. edu.

This is an open access article distributed under the CC BY-NC-ND license (https://creativecommons.org/ licenses/by-nc-nd/4.0/).

https://doi.org/10.21273/HORTTECH04672-20 environmentally friendly practices or ecofriendly products in their gardens. Indeed, prior studies report gardener interest in participating in environmentally conscious gardening practices (Behe et al., 2010; Grebitus et al., 2017) and that gardeners preferred ecofriendly products (Behe et al., 2013; Fan and McCann, 2015; Yue et al., 2010). However, it is unlikely that decisions about practice adoption and product purchase decisions are independent; therefore, they should likely be considered jointly in empirical analyses. This study is the first to model outdoor home gardeners' use of multiple ecofriendly gardening practices and their preferences for multiple environmental attributes in gardening supply products. Specifically, this study considers outdoor home gardeners' use of six environmentally friendly gardening practices and their preferences for six gardening supply products attributes as a simultaneous choice.
The six gardening practices considered in this study are planting pollinator plants, composting, recycling gardening packaging, rainwater collectors, using organic gardening methods, and soil testing. The six gardening supply attributes are decreased need for fertilizer applications, decreased need for pesticides, decreased need for water, use of native plant species, organically produced, and recyclable packaging. A multiple indicator-multiple causes model (MIMIC) model with correlated error terms is used to jointly model the use of these practices and preferences for these attributes. The data used in this study are from a survey of 601 Tennessee outdoor home gardeners.

MIMIC model output includes practice choice and attribute preference probabilities. These probabilities are used to make predictive inferences, given respondent demographic characteristics and opinions. Respondent characteristics include age, education, and gender. Additional variables include annual gardening supply expenditures, types of information used to improve gardening experience, and respondent attitudes. Results from this analysis provide insights regarding which practices are more (or less) likely to be used and which gardening product attributes are more (or less) likely to be preferred. Factors influencing the propensity to choose a combination of ecofriendly gardening practices and to prefer garden supply products with specific environmental attributes are used to identify market segments within outdoor home gardeners who are more likely to adopt practices and/or prefer environmental attributes in garden supplies. These results are useful for more accurate target marketing of gardening supplies with environmental attributes. They are also helpful for focusing educational programs about the use of ecofriendly gardening practices. The results also may be helpful in targeting holistic educational programs that encourage both ecofriendly home gardening practices adoption and complementary use of environmentally friendly gardening supplies. Simultaneous consideration of ecofriendly practice use and preferences for environmental attributes in gardening supplies enables comparison and contrast of outdoor gardener characteristics of those who 
may be more likely to adopt ecofriendly practices, or to prefer to purchase products with environmental attributes, or to be both adopters and purchasers.

\section{Previous research}

Prior research finds that demographic variables influence willingness to adopt ecofriendly gardening practices and prefer environmentally friendly attributes in gardening products. For example, some prior research suggests women are more likely than men to participate in environmentally friendly gardening practices (Behe et al., 2010; Grebitus et al., 2017) and to prefer ecofriendly products (Fan and McCann, 2015; Yue et al., 2010); however, Campbell et al. (2020) found that, among U.S. consumers, being female had a negative effect on probability of choosing sustainable/organic fertilizer brands. Results by Yue et al. (2010) showed that age and willingness to pay for products with biodegradable packaging were positively correlated. A more recent U.S.-Canadian study suggests that individuals with stronger ecocentric values were more likely to be older (Yue et al., 2016). In contrast, findings by Behe et al. (2013) were that the gardener group gaining the most utility from an energy savings attribute in garden plants tended to be younger in age. Furthermore, Campbell et al. (2020) found age to have a negative effect on probability of choosing a sustainable/organic fertilizer brand. Prior research findings suggest that education and adoption of environmentally friendly behaviors and habits are positively related (Behe et al., 2010; Yue et al., $2010,2016)$. Khachatryan et al. (2017) found that more highly educated consumers were less likely to purchase conventional products in the presence of products that advertised attributes showing environmental benefits (e.g., pollinator friendly, sustainably sourced, water/energysaving, and organic). Several studies found that income is positively related with the use of ecofriendly gardening practices and preferences for environmentally friendly attributes in gardening products. Khachatryan et al. (2017) showed that households with relatively higher income were less likely to purchase conventionally grown florals when environmentally friendly alternatives were available. In addition, other studies found a positive correlation between income and preferences for sustainable plant options (Rihn et al., 2016) and packaging (Yue et al., 2010); however, Campbell et al. (2020) found that income had a negative effect on probability that consumers would choose a sustainable/organic brand of fertilizer. Note, in this study we use gardening supplies expenditures as a proxy for income.

With respect to information sources used by gardeners, Kelly and Wehry (2006) found that $\approx 53 \%$ of Pennsylvania home gardeners consulted with friends, neighbors, and family for information about gardening. Television programs and gardening magazines were used by $30 \%$ to $40 \%$ of the respondents, followed by county Cooperative Extension offices and Master Gardeners (fewer than 20\%), and Web sites $(10 \%)$. In this study, we include these information sources in the statistical model analyzing practice use and attribute preferences.

Consumer attitudes toward the environment influence lawn and garden product purchasing decisions (Hugie et al., 2012). Furthermore, Campbell et al. (2015) found that consumers who purchase organic produce are more likely to be familiar with the terms ecofriendly and sustainable. Kiesling and Manning (2010) found that consumers who self-affiliated as "environmentalists" were more likely to implement certain gardening practices, including avoiding use of pesticides and using natural fertilizers.

\section{Materials and methods}

Survey AND DATA COLlECTION. We conducted a survey of home outdoor gardeners using the online survey platform offered by Qualtrics (Provo, UT). The list frame, provided by Qualtrics, was composed of randomly selected Tennessee residents aged 18 years or older who self-identified as outdoor gardeners. In June 2018 , we conducted an online pretest survey in Qualtrics of 108 randomly selected respondents provided from a panel by Qualtrics who were Tennessee residents, aged 18 years or older, and self-identified as home gardeners. We modified the survey based on the pretest results, and fielded a full version of the survey in
July 2018 ( $\mathrm{n}=612$ responses, with 601 usable in our statistical analysis). The survey instrument was approved by the University of Tennessee Institutional Review Board (UTK IRB18-04526-XM).

The survey asked respondents questions about their participation in outdoor home gardening, the importance of environmentally friendly attributes on purchase of gardening supplies, and participation in $\mathrm{eco}^{-}$ friendly outdoor gardening practices. The survey also elicited information about the use of gardening information, attitudes about gardening and the environment, household expenditures, and gardener demographics.

Respondents were asked if they planted pollinator plants (Pollinators), composted (Composting), recycled gardening packaging (Recycling), used rainwater collectors (Rainwater), used organic gardening practices (Organic Gard), or had tested their garden soil (Soil Testing). A dummy variable identified positive responses ( $1=$ yes, $0=$ no). Opinions about the importance of ecofriendly attributes of gardening products was elicited with a series of Likert scale questions ( $1=$ not important at all, $5=$ extremely important). For the purposes of modeling, importance the gardener places on each of the six attributes within the MIMIC modeling framework (discussed later in this article), a dummy variable was created for each attribute such that if the respondent indicated they believed the attribute was somewhat or extremely important by selecting 4 or 5 on the Likert scale, the attribute was assigned " 1 ," and " 0 " otherwise. These attributes are displayed in Table 1 as Decr Need Fertil, Decr Need Pestic, Decr Need Water, Native Species, Prod Organically, and Recyclable Pkg.

Respondents were asked about sources of information they obtained for making home gardening decisions. These included social media/ Internet; other gardeners; television, magazines, and newspapers; or extension/Master Gardener sources. Dummy variables were created for each Social Media/Internet, Other Gardeners, TV Magazines, and Extension/Master Gardener, in which the dummy variable was " 1 " if they used the particular source and " 0 " otherwise (Table 1).

The survey also included a section to collect information on demographics 
Table 1. Summary statistics for outdoor home gardener preferences for environmentally friendly attributes in gardening supplies, use of ecofriendly gardening practices, and selected demographics, attitudes, and expenditure patterns from a 2018 survey of Tennessee outdoor home gardeners $(n=601)$.

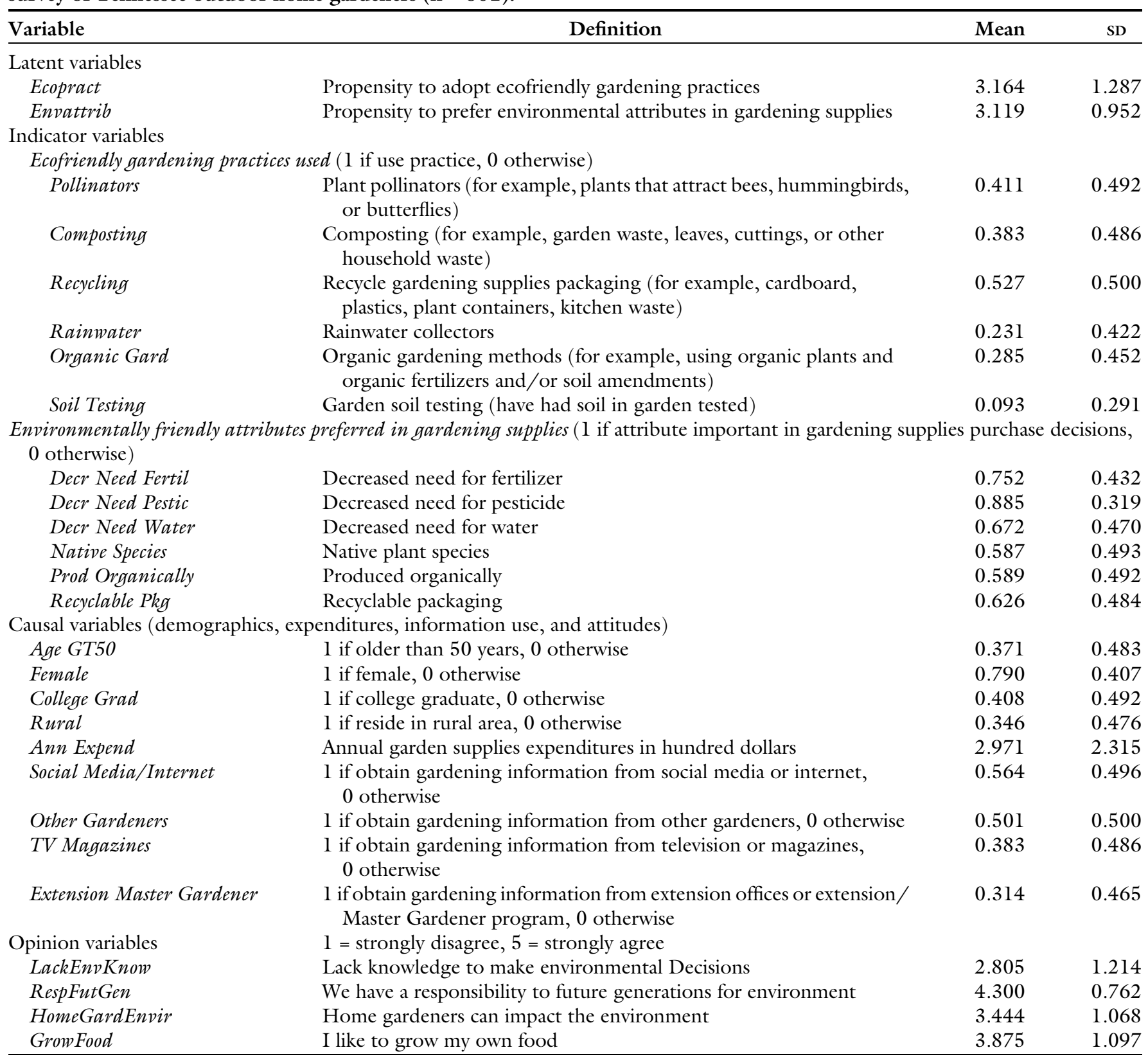

attributes. Demographic variables include respondent age (Age GT50), gender (Female), level of education (College Grad), place of residence ( $R u$ $\mathrm{ral}$ ), and annual expenditures on gardening supplies (Ann Expend).

Respondents were also asked a series of questions regarding attitudes toward gardening and the environment using a Likert agreement scale $(1=$ strongly disagree, $5=$ strongly agree) (Table 1 ). These include selfperceived knowledge assessment for making environmental decisions (LackEnvKnow), perceived responsibility to future generations for the environment (RespFutGen), perceived home gardener impact on the environment (HomeGardEnvir), and preferences for growing their own food (GrowFood). A copy of the survey instrument is available from the authors on request.

MIMIC MODEL. We uSe a MIMIC model with correlated errors to estimate the relationship between respondent demographic characteristics, the propensity to adopt the gardening practices considered, and preferences for the garden supplies attributes examined here. MIMIC models consist of structural and measurement equations (Skrondal and Rabe-Hesketh, 2004). MIMIC models are useful when there are multiple outcomes reflecting underlying latent variables (or propensities), as well as multiple causes (i.e., demographic variables). The type of model used in this study, the MIMIC model, is similar to a multinomial logit model. The advantage of using a MIMIC model rather than a series of multinomial logits is that it admits arbitrary correlation between groups of questions that are related through 
latent variables. The relationships in the MIMIC model in this study are illustrated in Fig. 1.

In the case of our study, we measured multiple indicators (or outcomes on selected binary choices), the probabilities of using six ecofriendly gardening practices or six preferring environmental garden supply product attributes, which are defined in Table 1 and illustrated in the boxes on the far right side of Fig. 1 . The indicator variables are related to underlying latent variables that we call Ecopract (the respondent's propensity to use ecofriendly gardening practices) and Envattrib (the respondent's attraction toward gardening supply products imbued with environmentally friendly attributes, defined at the top of Table 1 and shown in the middle of Fig. 1). The latent variables Ecopract and Envattrib are unobserved and estimated by the MIMIC model. These variables are constructed in a similar way that factor scores are from principal component or factor analysis. These two latent variables proxy the propensity to use ecofriendly gardening practices and propensity to prefer gardening products with environmental attributes, with larger values reflecting greater propensity. The latent variables are related to the causal variables $\mathrm{X}$ (defined at the bottom of Table 1 and illustrated in the left box of Fig. 1) through two structural regression equations:

$$
\begin{aligned}
\text { Ecopract }= & \beta_{1}^{P} \text { Age GT50 }+\ldots \\
& +\beta_{k}^{P} \text { GrowFood }+\mathrm{s}^{P} \\
\text { Envattrib }= & \beta_{1}^{A} \text { Age GT550 }+\ldots \\
& +\beta_{k}^{A} \text { GrowFood }+\mathrm{s}^{A}
\end{aligned}
$$

where $\beta^{P}=\left(\beta_{1}^{P}, \ldots, \beta_{k}^{P}\right)$ and $\beta^{A}=$ $\left(\beta_{1}^{A}, \ldots, \beta_{k}^{A}\right)$ are vectors of parameters to be estimated and $s^{P}$ and $s^{A}$ are random error terms (Bollen, 1989). For the purposes of identification, the variances of the error terms are restricted to one.

The relationships between the 12 indicator variables and the two latent variables are then estimated with 12 logit regression equations (measurement equations). If the estimated coefficient on the latent variable in a practice's or attribute's measurement logit equation is significant, then the practice or attribute is considered a good indicator of the underlying latent variable.

Six measurement logistic regressions relate the indicator variables (use of the six ecofriendly practices), and the latent variable, Ecopract. The probabilities of selecting each ecofriendly gardening practice are as follows:

$$
\operatorname{Pr}(\text { Pollinators }=1)=F^{\Lambda}\left(\lambda_{1}^{P} \times \text { Ecopract }\right)
$$

$$
\operatorname{Pr}(\text { SoilTesting }=1)=F^{\Lambda}\left(\lambda_{6}^{P} \times \text { Ecopract }\right)
$$

where $F^{\Lambda}$ is the logistic cumulative distribution function and $\lambda_{1}^{P}, \ldots, \lambda_{6}^{P}$ are the vectors of parameters to be estimated. Similarly, the probabilities of selecting each environmental attribute

\section{Structural Equations Regressions}

\section{Measurement Equations}

Logits
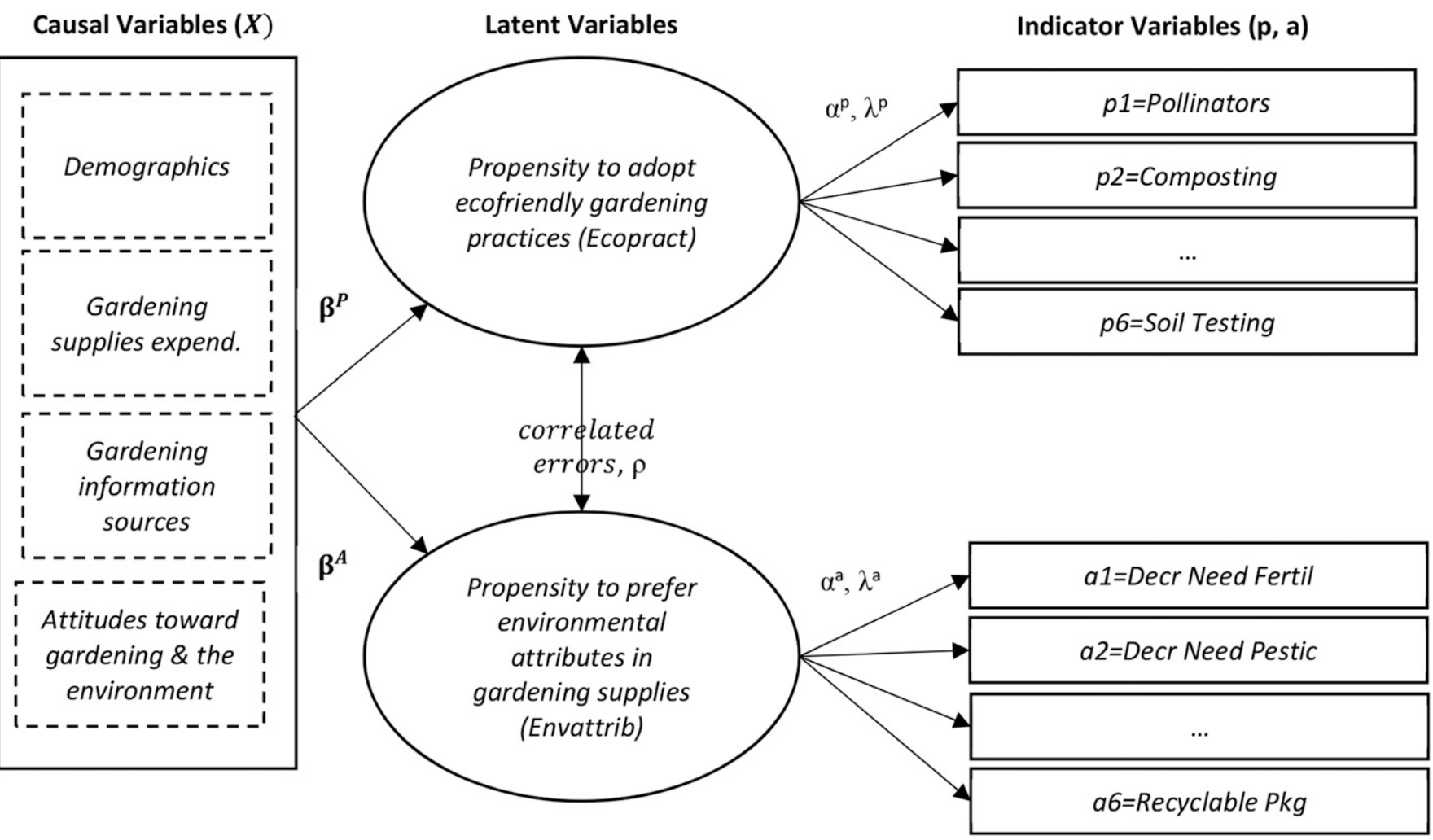

Fig. 1. Multiple indicator-multiple causes (MIMIC) model of outdoor home gardener propensity to prefer gardening supplies with environmental benefits and propensity to adopt ecofriendly gardening practices. 
are related to Envattrib through six logit measurement equations such that

$$
\begin{gathered}
\operatorname{Pr}(\text { Decr Need Fert }=1) \\
\quad=F^{\Lambda}\left(\lambda_{1}^{A} \times \text { Envattrib }\right) \\
\operatorname{Pr}(\text { Recyclable Pkg }=1) \\
\quad=F^{\Lambda}\left(\lambda_{6}^{A} \times \text { Envattrib }\right)
\end{gathered}
$$

where $\lambda_{1}^{A}, \ldots, \lambda_{6}^{A}$ are the vectors of parameters to be estimated.

The disturbance terms of the structural regressions, $\varsigma^{P}$ and $\varsigma^{A}$, and errors from their respective measurement logit regressions, $\varepsilon_{1}^{P}, \ldots, \varepsilon_{6}^{P}$ and $\varepsilon_{1}^{A}, \ldots, \varepsilon_{6}^{A}$ are assumed to be independent and identically distributed random variables with an expected value of zero and a constant variance $\theta_{j}=\pi^{2} / 3$ (Dell'Anno and Schneider, 2003; Joreskog and Goldberger, 1975; Lambert et al., 2015). The parameter $\rho$ is the correlation coefficient between the error terms $s^{P}$ and $s^{A}$.

The statistical software STATA (release 14; StataCorp, College Station, TX) was used to estimate the bivariate MIMIC model. Specifically, STATA's generalized structural equation modeling procedure (gsem) was used to estimate the MIMIC model. The procedure uses maximum likelihood to estimate the model parameters. Estimation details can be found in the gsem documentation.

Marginal effects (ME) were estimated to examine the effects of gardener demographics and other structural variables in $\mathrm{X}$ on the probability of a home gardener to use a practice or prefer a garden supply attribute. A marginal effect measures the change in probability of selecting an attribute or practice, given a oneunit change in the causal variable. For example, the marginal effects of the $k$ th causal variable on the probability of using an ecofriendly practice is

$$
\begin{gathered}
\partial \operatorname{Pr}(\text { Pollinators = } 1) / \partial X_{k} \\
=f^{\Lambda}\left(\lambda_{1}^{P} \times \text { Ecopract }\right) \times \beta_{k}^{P} \\
\partial \operatorname{Pr}(\text { Soil Testing }=1) / \partial X_{k} \\
\quad=f^{\Lambda}\left(\lambda_{6}^{P} \times \text { Ecopract }\right) \times \beta_{k}^{P}
\end{gathered}
$$

where $f^{\Lambda}$ is the logistic probability density function. Similar calculations are used to calculate the marginal effects of the $k$ th causal variable on the probability of preferring the environmental attributes in garden supplies.

Using the estimated coefficients from the logit models in Table 2, along with Eqs. [3] and [4] and Eqs. [5] and [6], and the respondent data, we developed probability response curves for adopting each practice and preferring each product attribute across varying levels of the latent variables Ecopract and Envattrib, respectively. The probability curves illustrate which practices are more or less likely to be used and which attributes hold broader (or narrower) appeal among gardeners of varying propensities to use ecofriendly gardening practices and to prefer environmental attributes.

We also calculated a reduced form equation that enables measurement of the effects of the causal variables on using the probabilities of using the ecofriendly practices or preferring the environmental attributes. These reduced form equations are useful because they can then be used to project how the probabilities of using the ecofriendly practices (or preferring the attributes) change, given changes in gardener demographics, expenditures, information use, or attitudes. Substituting Eq. [1] into Eqs. [3] and [4] and Eq. [2] into Eqs. [3] and [4] yields the reduced forms for the predicted probability of using each ecofriendly practice or preferring each environmental attribute as a function of the causal variables. Examples for the reduced forms for predicted probabilities of using the ecofriendly practices are as follows:

$$
\begin{aligned}
\operatorname{Pr}(\text { Pollinators }=1)= & F^{\Lambda}\left(\lambda _ { 1 } ^ { P } \left[\beta_{1}^{P}\right.\right. \text { Age GT50 } \\
& \left.\left.+\ldots+\beta_{k}^{P} \text { GrowFood }\right]\right) \\
\operatorname{Pr}(\text { Soil Testing }=1)= & F^{\Lambda}\left(\lambda _ { 6 } ^ { P } \left[\beta_{6}^{P}\right.\right. \text { Age GT50 } \\
& \left.\left.+\ldots+\beta_{k}^{P} \text { GrowFood }\right]\right)
\end{aligned}
$$

The same procedure (substituting Eq. [2] into Eqs. [5] and [6]) is used to calculate the reduced form for the probabilities of preferring each attribute as a function of the causal variables.

These reduced form probabilities were used to illustrate how different market profiles for home gardeners could affect these probabilities. Two gardener profiles were developed for each structural equation (two for $E c 0^{-}$ pract and two for Envattrib). The profile for a gardener who is very unlikely (very likely) to adopt the ecofriendly practices is Profile 1 (Profile 2 ). The profile for a gardener who is very unlikely (very likely) to prefer the environmental attributes is Profile 3 (Profile 4). The profiles are developed based on the signs of the estimated coefficients $\left(\beta^{P}\right.$ and $\left.\beta^{A}\right)$ for the causal variables $(\mathrm{X})$ in the estimated structural regression equations in Table 2 . Because the signs of the coefficients on latent variables in the measurement logits are positive, this means the sign of the effect of the causal variable on the probability of using the practices or preferring the attributes will be determined by the sign on the coefficient of that causal variable in the structural regressions for Ecopract and Envattrib. For example, the estimated coefficient on the variable for female gender $\left(\mathrm{Fe}^{-}\right.$ male) is negative in the structural equation for Ecopract; therefore, female gender has a negative effect on probabilities of gardeners using the ecofriendly practices. Hence, to project probabilities of using the ecofriendly practices using Eqs. [9] and [10], for Profile 1 gardeners, a value of " 1 " is used for Female, whereas for a Profile 2 gardener, a value of " 0 " is used for Female. A similar process is used in setting the values for each of the causal variables in each profile. The demographic characteristics, expenditures, information use, and attitudes for each profile are presented. Distributions around the predicted probabilities were simulated with 15,000 draws each using the Krinsky-Robb (Krinsky and Robb, 1986). The 50th percentile and $95 \%$ confidence intervals were calculated for the simulated probabilities of choosing the practices by Profiles 1-2 and choosing the attributes as important by Profiles 3-4. If the 95\% confidence intervals for Profiles 1 and 2 do not overlap, then the probability of Profile 2 using the practices is statically greater than Profile 1 . The same type of comparison can be made for the probability of choosing the attributes as important by Profiles 3 and 4 .

\section{Results}

RESPONDENT SUMMARY STATISTICS. Approximately $37 \%$ of the respondents 
Table 2. Estimated multiple indicator-multiple causes (MIMIC) model for outdoor home gardener propensity to use ecofriendly gardening practices and to prefer ecofriendly attributes in gardening supplies using data from a 2018 survey of Tennessee outdoor home gardeners $(n=601)$.

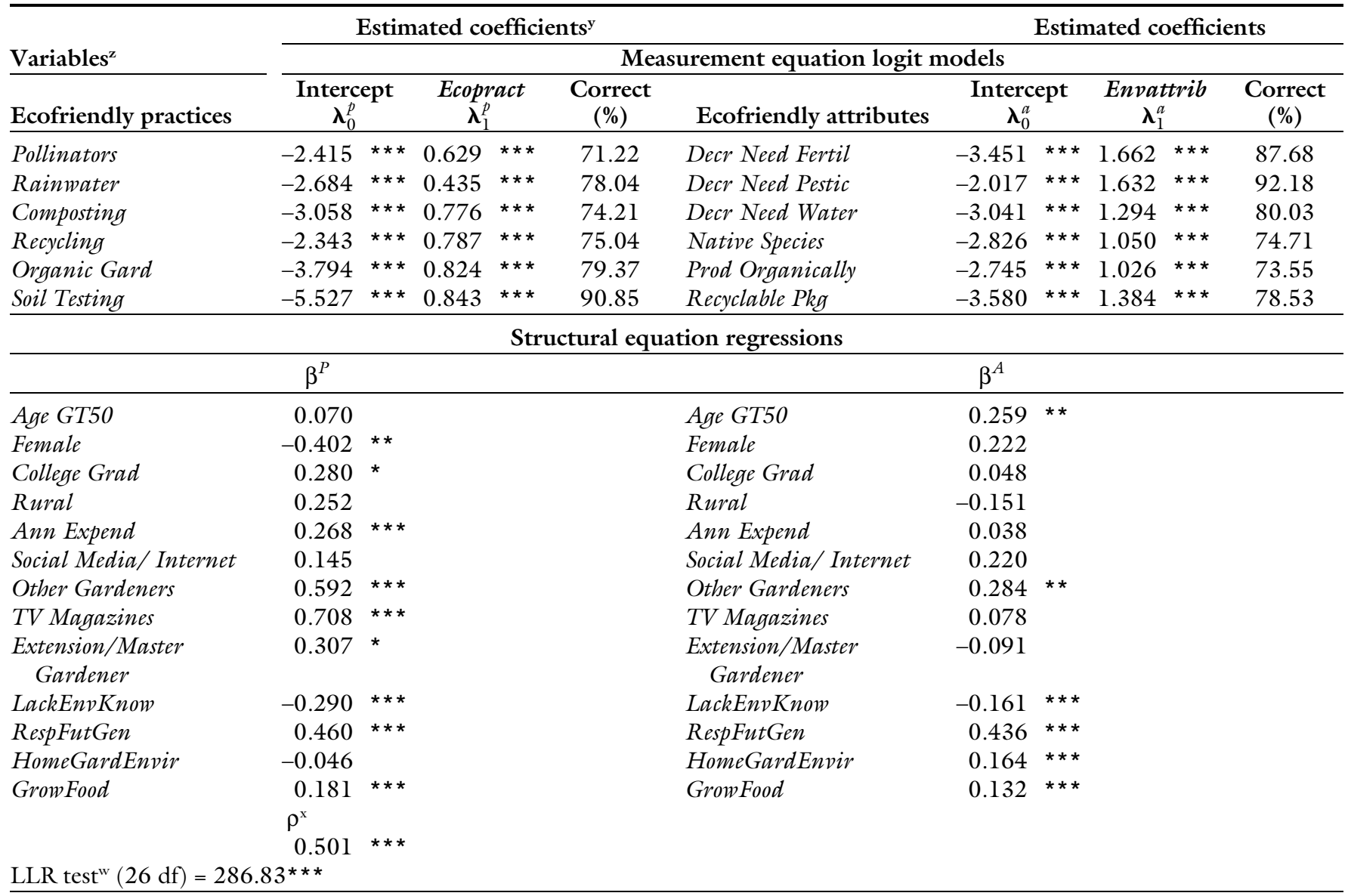

${ }^{\mathrm{z}}$ Variable definitions are provided in Table 1 .

y* $, * *, * *$ Significant at $P \leq 0.10,0.05$, or 0.01 , respectively.

${ }^{x}$ Correlation between the error terms of the regression portions of the MIMIC model for Ecopract and Envattrib.

${ }^{w}$ Log likelihood ratio test of the model against a model with an intercept only.

were older than 50 (Table 1). Most (79\%) respondents were women. Approximately $40 \%$ of the respondents were college graduates. From the National Gardening Association 2014 survey, the average U.S. gardener was female, 45 years or older, and held a college degree or had some college education (National Gardening Association, 2014). The present sample appears to correspond with these $\mathrm{Na}-$ tional Gardening Survey averages. In 2018 , the average amount spent per U.S. household on lawn and gardening activities was $\$ 503$, whereas the present study found an average expenditure on gardening supplies of $\$ 297$ for 2018 (Cohen, 2018). It should be noted that our estimate is for Tennessee outdoor home gardeners, not a U.S. average. Also, our question asked specifically about gardening supplies and did not include lawn care services or supplies expenditures, hence the survey respondent's estimates of their expenditures would likely be lower than the U.S. estimate that does include lawn care.

The gardening practice used most frequently was Recycling (53\%), followed by Pollinators $(41 \%)$ (Table 1). The least commonly used practices were rainwater collectors, Rainwater (23\%) and Soil Testing $(9 \%)$. Among the attributes evaluated in this study, gardening products that decreased the amount of pesticides applied (Decr Need Pestic) was cited most frequently as important $(89 \%)$, followed by decreased need for fertilizer, Decr Need Fertil (75\%). The least commonly cited attributes were $\mathrm{Na}$ tive Species (59\%) and Prod Organically $(59 \%)$. For information sources used by home gardeners, the most commonly used source was Social Media/Internet (56\%), followed by Other Gardeners (50\%). Although 38\% used TV Magazines, 31\% used Extension/Master Gardener sources.

Home gardener opinions about the environment and gardening were elicited with a Likert agreement scale, where $\mathrm{l}=$ strongly disagree, and $5=$ strongly agree. Concerning environmental knowledge, respondents tended to disagree that they lacked sufficient knowledge to make environmental decisions (LackEnvKnow, mean $=2.8$ ). Respondents also tended to have very strong views that we have a responsibility to steward the environment for future generations $($ RespFutGen, mean $=$ 4.3). Respondents also tended to agree that home gardeners can affect the environment (HomeGardEnvir, mean $=3.4)$, and that they like to 
Table 3. Marginal effects of gardener demographics, expenditures, information use, and attitudes on probabilities of using six ecofriendly gardening practices and preferring the six environmental attributes in gardening supplies using data from a 2018 survey of Tennessee outdoor home gardeners.

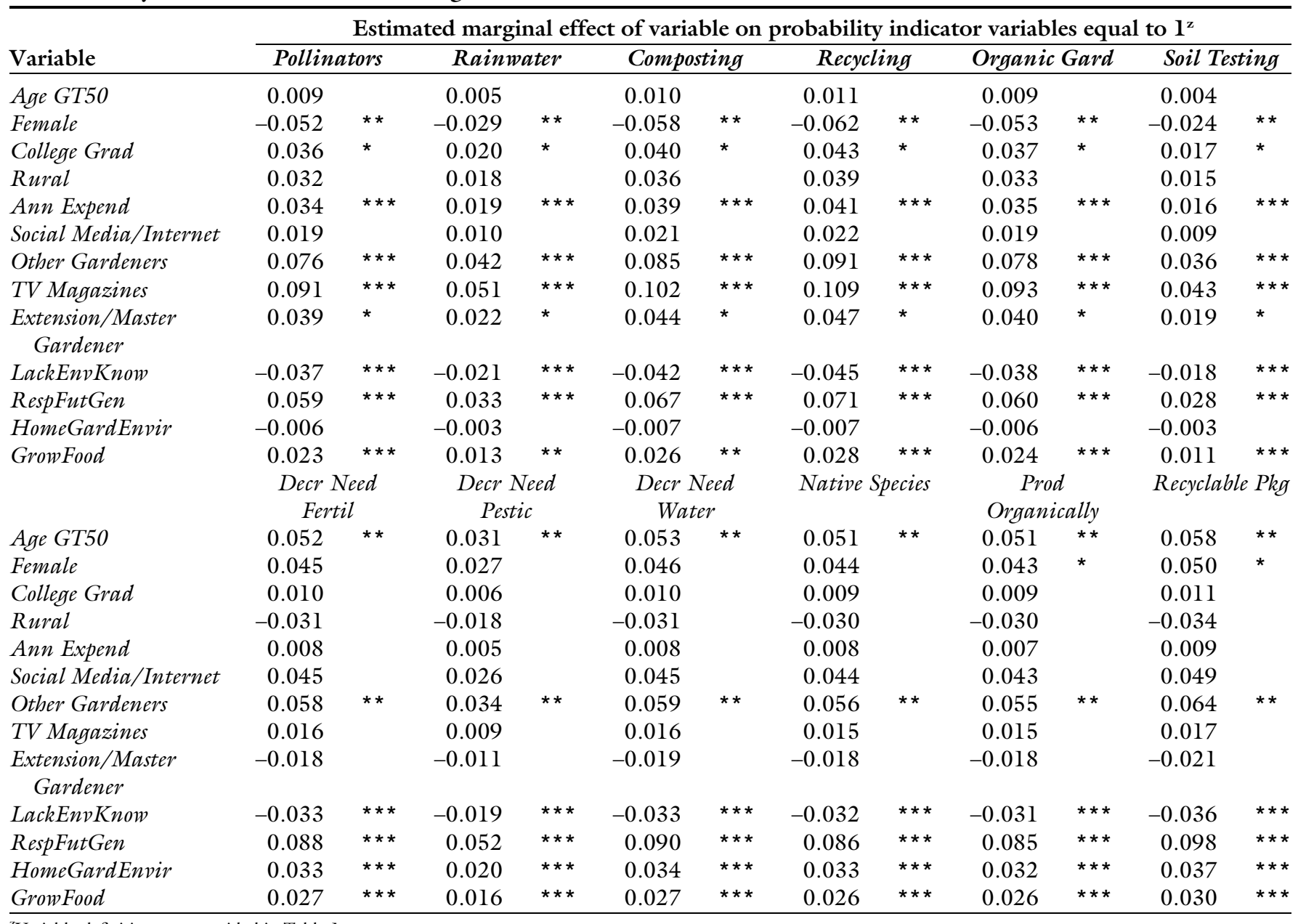

${ }^{\mathrm{z}}$ Variable definitions are provided in Table 1 .

y*,$* * * * *$ Significant at $P \leq 0.10,0.05$, or 0.01 , respectively.

${ }^{\mathrm{x}}$ Standard errors around the marginal effects to conduct the statistical tests were obtained by the Delta method (Greene, 2018).

garden to grow their own food (GrowFood, mean $=3.9$ ).

EsTimated MIMIC MODEL. The log-likelihood ratio test (LLR) of the model against the intercept-only model indicates that the covariates and latent variable were significantly related with the propensity to use certain garden practices and preferences for the garden supplies attributes analyzed here (Table 2). The estimated logit measurement equations are shown in the upper portion of Table 2. Each of the estimated coefficients on the latent variables Ecopract and Envattrib ( $\lambda^{p}$ and $\left.\lambda^{a}\right)$ are significant. This result suggests that the six practices are good indicators of the propensity to use ecofriendly gardening practices, Ecopract, and that the six attributes are good indicators of the propensity to prefer ecofriendly attributes, Envattrib, in gardening supplies. The percentage of observations correctly classified for each of practices indicator ranges from $71 \%$ for Pollinators to $91 \%$ for Soil Testing. The percentage of observations correctly classified by the MIMIC logits for each of the attribute indicator variables ranges from $73 \%$ for Prod Organically to $92 \%$ for Decr Need Pestic.

Several of the estimated coefficients on demographic and other causal variables (defined in Table 1 ) are significant in the structural equation for Ecopract (Table 2). Contrary to findings by Behe et al. (2010) and Grebitus et al. (2017), but similar to those by Campbell et al. (2020), female gender has a negative influence on propensity to use ecofriendly gardening practices (Ecopract). As with several prior studies' findings (Behe et al., 2010; Yue et al., 2010,
2016), higher educational attainment (College) was found to have a positive influence on Ecopract. Higher annual expenditures on gardening supplies (Ann Expend) were positively correlated with the latent variable Ecopract. This result is similar to findings regarding income by Khachatryan et al. (2017), Rihn et al. (2016), and Yue et al. (2010). Self-perceived lack of environmental knowledge (LackEnvKnow) was negatively correlated with the latent variable Ecopract. Also, if the gardener more strongly agrees that the current generation has an environmental stewardship responsibility to future generations (RespFut$G e n)$ and they like to grow their own food (GrowFood), they are more likely to exhibit an affinity toward adopting ecofriendly practices (Ecopract). These findings regarding environmental knowledge and concern support 
Table 4. Profiles of outdoor home gardeners with lower and higher propensities to use ecofriendly practices and prefer ecofriendly attributes and predicted probabilities of using six practices and preferring six attributes for these profiles using data from a 2018 survey of Tennessee outdoor home gardeners. ${ }^{\mathrm{z}}$

\begin{tabular}{|c|c|c|c|c|c|c|}
\hline & \multicolumn{2}{|c|}{ Ecopract } & & \multicolumn{3}{|c|}{ Envattrib } \\
\hline & $\begin{array}{c}\text { Profile 1 } \\
\text { (very unlikely) }\end{array}$ & $\begin{array}{c}\text { Profile } 2 \\
\text { (very likely) }\end{array}$ & & $\begin{array}{c}\text { Profile } 3 \\
\text { (very unlikely) }\end{array}$ & $\begin{array}{c}\text { Profile } 4 \\
\text { (very likely) }\end{array}$ & \\
\hline Age GT50 & No & Yes & Age GT50 & No & Yes & \\
\hline Female & Yes & No & Female & No & Yes & \\
\hline College Grad & No & Yes & College Grad & No & Yes & \\
\hline Social Media/Internet & No & Yes & Social Media/Internet & No & Yes & \\
\hline Other Gardeners & No & Yes & Other Gardeners & No & Yes & \\
\hline TV Magazines & No & Yes & TV Magazines & No & Yes & \\
\hline Extension/Master Gardener & No & Yes & Extension/Master Gardener & Yes & No & \\
\hline LackEnvKnow & Agree & Disagree & LackEnvKnow & Agree & Disagree & \\
\hline Pollinators & 0.086 & 0.717 & ** Decr Need Fert & 0.086 & 0.952 & ** \\
\hline Composting & 0.047 & 0.745 & * Decr Need Pestic & 0.279 & 0.987 & ** \\
\hline Recycling & 0.091 & 0.863 & * Decr Need Water & 0.100 & 0.877 & ** \\
\hline Rainwater & 0.066 & 0.408 & ** Native Species & 0.105 & 0.775 & * * \\
\hline Organic Gard & 0.023 & 0.643 & * Prod Organically & 0.112 & 0.773 & ** \\
\hline Soil Testing & 0.004 & 0.261 & ** Recyclable Pkg & 0.064 & 0.855 & ** \\
\hline
\end{tabular}

past studies' findings suggesting a positive influence of environmental concern on ecofriendly gardening decisions (Campbell et al., 2020; Hugie et al., 2012; Kiesling and Manning, 2010). With respect to the effects of information sources, the coefficients on Other Gardeners, TV Magazines, and Extension/Master Gardener are each positive and significant.

As for the effects of the causal variables on propensity to prefer the environmental attributes in gardening supplies, the estimated coefficient on AgeGT50 is positive and significant in the structural equation for Envattrib. This finding suggests older gardeners exhibit a greater propensity to prefer ecofriendly attributes promoting gardening supplies. This finding is similar to that by Yue et al. (2016). Although self-perceived lack of environmental knowledge, LackEnvKnow, negatively influences Envattrib, respondents who believe that current generations have a stewardship responsibility to future generations for the environment (RespFutGen), that home gardeners can affect the environment (HomeGardEnvir), and who like to grow their own food (GrowFood) are more likely to prefer environmental attributes in garden supplies. These findings imply that environmental knowledge and concern positively influence propensity to prefer environmental attributes in gardening supplies and are similar to those by Campbell et al. (2020), Hugie et al. (2012), and Kiesling and Manning (2010). Also, use of information from other gardeners (Other Gardeners) positively influences Envattrib, suggesting gardeners seek out information from other gardeners to make decisions about purchasing gardening supplies with environmental attributes.

Interesting patterns emerge when the significance of the demographic, expenditures, information, and attitude variables across Ecopract and Envattrib are compared. In general, a greater number of demographic and expenditure variables significantly influence practice use than attribute preference. Male gender, college graduate level of education, and greater gardening expenditures positively influenced practice use, but not preferences for attributes. One possible explanation is that products with environmental attributes may hold appeal across a relatively broad cross-section of outdoor home gardeners, whereas implementation of practices may appeal to a more specialized segment of outdoor home gardeners. An exception to this is gardener age, with home gardeners who are older than 50 years being more likely to prefer environmental attributes, but age older than 50 years having no significant effect on practice use. One possible explanation is that older gardeners may favor supporting environmentally friendly gardening through their purchases. Their environmental preferences for practices may be weighed against the labor required to implement them. However, further research would be needed to fully investigate this possibility.

Although information from other gardeners influences both practice use 
and preferences for attributes, other information sources, including television and magazines and extension or Master Gardener programs, significantly influence practice use but not preferences for garden supply attributes. These results could indicate that home gardeners look to these particular sources for information about "howto" guides, instructions, and illustrations for implementing ecofriendly gardening practices. Also, the results could suggest outdoor home gardeners may use a wider set of information sources for advice on practices, but a more narrow set, other gardeners, for making environmentally friendly product choices. Gardeners may rely more heavily on "word-of-mouth" recommendations from other gardeners for making product choices. Furthermore, an interesting finding is that although attitudes about environmental knowledge and responsibility to future generations for the environment both positively influence Ecopract and Envattrib, this is not the case for agreement with home gardeners being able to influence the environment with their actions. Although the coefficient on HomeGardEnvir is not significant in the Ecopract structural equation, it is positive and significant in the equation for Envattrib. One possible interpretation of this result may be that home gardeners believe their actions collectively as gardening product purchasers may have more effect on the environment than if they individually use the specified ecofriendly practices. However, further research would be needed to fully explore this possibility.

The estimated MEs of causal variables (defined in Table 1 ) are shown in Table 3 . The MEs are interpreted as the change in the probability of the indicator variable being "l" (of using a practice or preferring an attribute) with a one-unit change in the causal variable. For example, the ME of female gender (Female) on using rainwater collectors (Rainwater) is -0.029 , hence female gardeners are $2.9 \%$ less likely to use this practice than male gardeners.

The marginal effect on age (AgeGT50) ranges from 3.4\% for Decr Need Pestic to $5.8 \%$ for Recyclable Pkg. Gender (Female) has a $-2.4 \%$ effect on Soil Testing, with MEs magnitudes ranging up to $-6.2 \%$ for Recycling. Being a college graduate (College Grad) has positive marginal effects on soil testing and recycling, ranging in magnitude from $1.7 \%$ for Soil Testing to $4.3 \%$ for Recycling. The marginal effects of annual gardening supply expenditures (Ann Expend) suggest that for each additional $\$ 100$ of gardening expenditures the probability of using Soil Testing increases by $1.6 \%$ and the probability of using Recycling increases by $4.1 \%$.

With respect to the effects of the use of information sources, the use of information from other gardeners (Other Gardeners) has positive MEs both on the probabilities of using the practices and on the probability of preferring the attributes. For the attribute preferences, only the MEs on Other Gardeners are significant at the $90 \%$ confidence level or greater. The smallest ME is $3.4 \%$ for the probability of preferring the attribute Decr Need Pestic, whereas the largest ME for Other Gardeners is on the probability of using the practice Recycling at $9.1 \%$.

The MEs of TV Magazines and Extension/Master Gardener are positive and significant for the probabilities of using all the evaluated ecofriendly practices. The smallest of these is for Extension/Master Gardener on the probability of using Soil Testing at $1.9 \%$, and the largest is for using TV Magazines on Recycling at $10.9 \%$.

The effects of lack of self-perceived environmental knowledge on the probabilities of using the six practices and preferences for the six attributes are presented in Table 3 . The largest ME for LackEnvKnow is on the probability of using Recycling $(-4.5 \%)$ and the smallest is on the probability of using Soil Testing $(-1.8 \%)$ and for preferring Decr Need Pestic $(-1.9 \%)$. The variables capturing gardener environmental attitudes have MEs ranging from $1.1 \%$ for GrowFood on the probability of using Soil Testing to $9.8 \%$ for RespFutGen on the probability of preferring $R e^{-}$ cyclable Pkg.

Probabilities of Using the PRACTICES AND PREFERRING THE ATTRIBUTES. The predicted probabilities of the home gardener using the six practices are graphed over increasing propensity to use ecofriendly gardening practices (Ecopract) (Fig. 2). Recycling of gardening supplies packaging (Recycling) is adopted most widely across the outdoor home gardeners at both lower and higher levels of Ecopract. This practice's adoption rises above $50 \%$ use at even moderate levels of Ecopract. At lower levels of Ecopract, the practice with the next highest probability of use is planting pollinator plants (Pollinators), but as the respondent propensity to use ecofriendly gardening practices rises, the probability of using composting (Composting) rises more quickly than planting pollinator plants. The practices for which probability is lowest

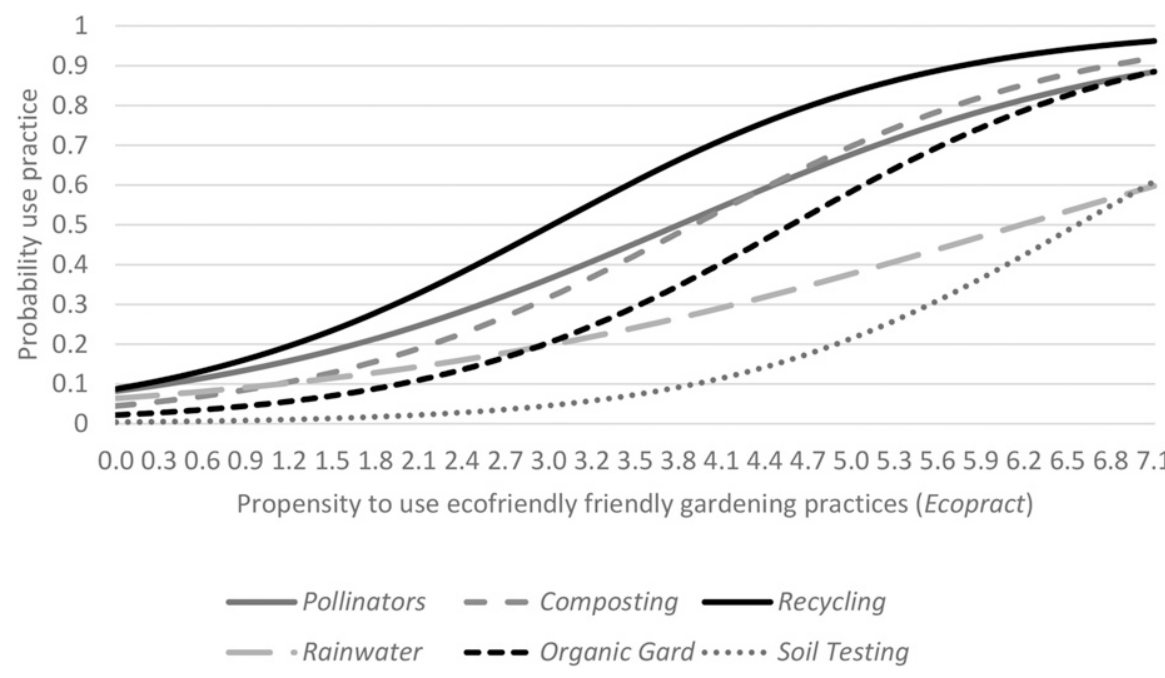

Fig. 2. Predicted probabilities of outdoor gardeners using pollinators, composting, recycling garden supplies packaging, rainwater collectors, organic gardening practices, or soil testing across varying levels of propensity to use ecofriendly gardening practices (Ecopract) using data from a 2018 survey of Tennessee outdoor home gardeners. 
are use of rainwater collectors ( Rainwater) and soil testing (Soil Testing). These two practices reach only $50 \%$ adoption at high levels of Ecopract, suggesting their use is primarily reserved to those who are most intensely interested in using ecofriendly gardening practices.

Figure 3 displays the predicted probabilities of the home gardener citing the six attributes as important graphed over increasing propensity to prefer ecofriendly attributes in gardening supplies (Envirattrib). The attribute Decr Need Pestic is the most widely preferred across both lower and higher levels of Envirattrib. The probability of selecting Recyclable Pkg rises next, followed by Decr Need Water. The probabilities of selecting Prod Organically and Native Species follow similar trajectories as Envattrib rises. These two attributes have the lowest probabilities of being selected as important of the attributes examined, suggesting these attributes are more limited in their appeal, primarily to those most concerned about purchasing gardening supplies with ecofriendly attributes.

The efFects OF GaRdener MARKET PROFILES ON PROBABILITIES OF USING THE PRACTICES AND PREFERRING THE ATTRIBUTES. The two profiles created for Ecopract, Profiles 1 and 2, are shown in the second and third columns of the upper half of Table 4 (see Table 1 for variable definitions). The two profiles created for Envattrib, Profiles 3 and 4, are shown in the fifth and sixth columns. Profile 1 (Profile 2), is for a gardener who is very unlikely (very likely) to use the ecofriendly gardening practices. The Profile 1 (Profile 2) outdoor gardener is 50 years old or younger (over 50), female (male), not a college graduate (a college graduate), does not reside in a rural area (rural residence) with $\$ 200$ (\$400) in annual gardening supplies expenditures, does not use (uses) social media or the Internet, other gardeners, TV or magazines, or extension or Master Gardener program information sources, disagrees (agrees) that she or he is knowledgeable about environmental issues, and in general agrees (disagrees) that they are concerned about environmental issues.

Profile 3 (Profile 4 ) is a gardener who is very unlikely (very likely) to prefer the ecofriendly attributes. The Profile 3 (Profile 4) gardener is aged 50 years or younger (aged older than 50 years), male (female), not a college graduate (college graduate), lives in a rural area (does not live in a rural area), and spends $\approx \$ 200 \quad(\$ 400)$ per year on gardening supplies. The Profile 3 (Profile 4) gardener uses (does not use) social media/Internet, other gardeners, and TV or magazines as information sources. The Profile 3 (Profile 4) gardener uses (does not use) information from extension/Master Gardener programs and is self-perceived to lack (to not

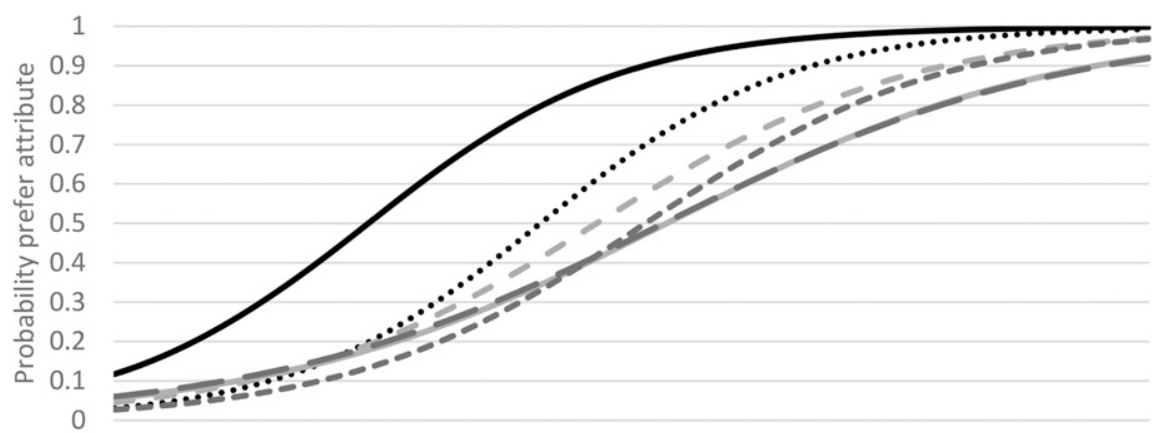

0.0 0.2 0.4 0.6 0.8 1.0 1.3 1.5 1.7 1.9 2.1 2.3 2.5 2.7 2.9 3.1 3.4 3.6 3.8 4.0 4.2 4.4 4.6 4.8 5.0 Propensity to prefer environmental attributes in gardening supplies (Envattrib)

...... Decr Need Fert

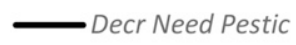

- Decr Need Water

Native Species

- Prod Organically

- - Recyclable Pkg

Fig. 3. Predicted probabilities of outdoor gardeners believing the attributes decreased need for pesticide, decreased need for fertilizer, decreased need for water, produced organically, native species, and recyclable packaging are important in making garden supply purchase decisions (Envattrib) using data from a 2018 survey of Tennessee outdoor home gardeners. lack) adequate knowledge to make environmental decisions. Profile 3 (Profile 4) gardeners disagree (agree) with the statements that we are responsible to future generations for the environment, home gardeners can impact the environment with their actions, and that they like to garden to grow foods.

The predicted probabilities of using each of the six gardening practices for the two profiles are in the second and third columns in the bottom half of Table 4 . The probabilities of using the six practices increase when moving from Profile 1 to Profile 2. For example, the probability of a gardener using pollinators (Pollinators) increases from 9\% for Profile 1 to $72 \%$ for Profile 2 . The probability of recycling garden supplies packaging increases from $9 \%$ to $86 \%$. The largest probability increase is projected when moving from Profile 1 to Profile 2 for recycling garden supplies packaging (Recycler) and composting (Composting), whereas the smallest probability increases are for rainwater collectors (Rainwater) and soil testing (Soil Testing). As shown in Table 4, for each practice, the $95 \%$ confidence intervals around the simulated probabilities for Profile 2 do not overlap with those of Profile 1 , indicating the Profile 2 probabilities are statistically greater than Profile 1 probabilities.

The probabilities of preferring the six attributes across the two profiles created for Envattrib (Profile 3 and Profile 4) are shown at the bottom of Table 4 in the fifth and sixth columns. An example interpretation of these probabilities is that preferences for decreased need for fertilizer rise from 9\% for Profile 3 to $95 \%$ for Profile 4 . When moving from Profile 3 to Profile 4, the largest increase in probability is for Decr Need Fertil, increasing from $9 \%$ to $95 \%$. The smallest increase is for Prod Organically, increasing from $11 \%$ to $66 \%$. As shown in Table 4 , for each attribute, the $95 \%$ confidence intervals around the simulated probabilities for Profile 4 do not overlap with those of Profile 3 , indicating the Profile 4 probabilities are statistically greater than Profile 3 probabilities.

\section{Discussion}

The results from this study suggest that preferences for ecofriendly 
attributes in gardening supplies and the use of ecofriendly gardening practices are positively correlated. Among the practices examined, the most widely used is recycling gardening supplies packaging and the least widely used is soil testing. For the garden supplies attributes, the most frequently cited as important for garden supplies purchases is decreased need for pesticides, whereas the least frequently cited is native plant species. The results suggest decreased need for pesticide has the widest appeal among the attributes studied, whereas organically produced and native species attributes appeal to a more specialized market segment that is most interested in ecofriendly gardening.

The results from this study help identify characteristics of market segments that have low and high propensity to prefer gardening products with environmental benefits and to use ecofriendly gardening practices. The differing effects of the gardener characteristics on the use of ecofriendly practices vs. choosing products with ecofriendly attributes provide some interesting insights. In general, a greater number of demographics influenced practice use vs. attribute preferences. This suggests a broader appeal of purchasing gardening supplies with the environmental attributes across a variety of gardener demographics compared with the ecofriendly practices considered in this study. Hence, the practices hold appeal to a more specialized segment of home gardeners. One potential explanation could be the additional labor required to implement the practices. Gardener gender and education level significantly influences practice use, but not preferences for the product attributes. Hence, this result suggests that more highly educated men are more likely to implement ecofriendly gardening practices. Higher expenditures are expected to positively influence preferences for gardening supply attributes, which in some cases, might sell for premium prices compared with conventional products. Surprisingly, gardening supplies expenditure levels positively influence practice use, but do not significantly affect preferences for the product attributes. One possibility is that gardeners may not have a very clear recall of their gardening supplies expenditures. Further research might more fully assess home gardeners' expenditures using a diary-recall-type survey instrument over multiple time periods. The finding that older age positively influences attribute preferences but not practice could suggest a labor concern associated with practice adoption among older gardeners. Older gardeners may prefer to shift toward more ecofriendly gardening through the products they purchase rather than practice adoption.

Among the sources of gardening information, the most commonly used is social media/Internet, followed by other gardeners. The use of gardening information, in general, positively influences ecofriendly practice use. As far as influence on preferences for the attributes, information from other gardeners is the only information source significantly affecting attribute preferences. This result could suggest that home gardeners are more likely to learn about ecofriendly attributes from other home gardeners and, also, that word of mouth is influential on purchase decisions. Furthermore, home gardeners may look to extension/Master. Lack of significance of social media and the Internet together may reflect differing informational uses of these two sources. For example, social media may be used more visually for gardening project ideas, whereas the Internet may be used more for information about how to do garden projects; however, additional research would be needed to fully evaluate disentangle how gardeners may use differing online platforms to obtain specific types of gardening information.

Both use of information from $\mathrm{TV}$ and magazines and also extension/Master Gardener information sources influence practice use, but not attribute preferences. One possible interpretation of this finding could be that TV home gardening programs and magazines, as well as extension/Master Gardener programs, may focus on "how to" implement ecofriendly practices, more so than products with specific attributes. Again, this merits additional research regarding the types of information home gardeners are gleaning from the various sources regarding practice use or ecofriendly product attributes.

It is important to note that this study has several limitations. First, it is limited to outdoor home gardeners in Tennessee. Study funding levels were prohibitive of expanding the geographic study area. A wider region of the United States should be considered in future research. Second, we did not ask questions gauging gardening or environmental knowledge, only a self-perceived environmental knowledge question. Hence, it is possible that some respondents may not be as familiar with some of the practice or attribute terminology used as others. Familiarity levels with and knowledge about the practices and attributes could affect how respondents answered regarding practice use and importance of attributes in making gardening supplies purchases. Additional research might account for differences in knowledge levels, particularly about the specific practices and attributes. Third, although this study provides insights into attributes home gardeners believe to be important, pricing, and other product attributes are not introduced into this analysis. Future research should introduce prices along with the attributes to elicit home gardener willingness to pay for the attributes.

\section{Literature cited}

Behe, B., B. Campbell, C. Hall, H. Khachatryan, J. Dennis, and C. Yue. 2013. Consumer preferences for local and sustainable plant production characteristics. HortScience 48:200-208.

Behe, B., B. Campbell, J. Dennis, C. Hall, R. Lopez, and C. Yue. 2010. Gardening consumer segments vary in ecopractices. HortScience 45:1475-1479.

Campbell, B., H. Khachatryan, B. Behe, J. Dennis, and C. Hall. 2015. Consumer perceptions of eco-friendly and sustainable terms. Agr. Resources Econ. Rev. 44:21-34.

Bollen, K.A. 1989. Structural equations with latent variables. Wiley, New York, NY.

Campbell, J., A. Rihn, and H. Khachatryan. 2020. Factors influencing home lawn fertilizer choice in the United States. HortTechnology 30:296-305.

Cohen, P. 2018. Your typical gardener is younger these days - and has a lot of questions. 10 July 2020. <https://www. globenewswire.com/news-release/ $2018 / 04 / 18 / 1480986 / 0 /$ en / Gardening-Reaches-an-All-Time-High. html>.

Dell'Anno, R. and F. Schneider. 2003. The shadow economy of Italy and other OECD countries: What do we know? J. 
Public Fin. Public Choice 21(2-3):97120.

Fan, Y. and L. McCann. 2015. Households' adoption of drought tolerant plants: An adaptation to climate change? Agr. Appl. Econ. Assoc./Western Agr. Econ. Assoc. Annu. Mtg., San Francisco, CA. 26-28 July 2015.

Greene, W. 2018. Econometric analysis. 8 th ed. Pearson, New York, NY.

Grebitus, C., I. Printezis, and A. Printezis. 2017. Relationship between consumer behavior and success of urban agriculture. Ecol. Econ. 136:189-200.

Hugie, K., C. Yue, and E. Watkins. 2012. Consumer preferences for low-input turfgrasses: A conjoint analysis. HortScience 47:1096-1101.

Joreskog, K. and A. Goldberger. 1975. Estimation of a model with multiple indicators and multiple causes of a single latent variable. J. Amer. Stat. Assoc. 70:631-639.
Kelly, K. and R. Wehry. 2006. Consumer interest in gardening topics and preferred information sources. J. Ext. 44 (2):2RIB7. 10 July 2020. <https://www.joe.org/ joe/2006april/rb7.php>.

Khachatryan, H., A. Rihn, B. Campbell, C. Yue, C. Hall, and B. Behe. 2017. Visual attention to eco-labels predicts consumer preferences for pollinator friendly plants. Sustainability 9:1743.

Kiesling, F. and C. Manning. 2010. How green is your thumb? Environmental gardening identity and ecological gardening practices. J. Environ. Psychol. 30:315-327.

Krinsky, I. and A. Robb. 1986. On approximating the statistical properties of elasticities. Rev. Econ. Stat. 68:715-719.

Lambert, D.M., K. Paudel, and J.A. Larson. 2015. Bundled adoption of precision agriculture technologies by United States cotton producers. J. Agr. Resource Econ. 40:325-345.

National Gardening Association. 2014. National gardening survey 2014 edition. Natl. Gardening Assoc., Williston, VT.
Rihn, A., H. Khachatryan, B. Campbell, C. Hall, and B. Behe. 2016. Consumer preferences for organic production methods and origin promotions on ornamental plants: Evidence from eye-tracking experiments. Agr. Econ. 47:599-608.

Skrondal, A. and S. Rabe-Hesketh. 2004. Generalized latent variable modeling: Multilevel, longitudinal, and structural equation models. Chapman \& Hall/ CRC, Boca Raton, FL.

Yue, C., C.R. Hall, B. Behe, B.L. Campbell, J.H. Dennis, and R.G. Lopez. 2010. Are consumers willing to pay more for biodegradable containers than for plastic ones? Evidence from hypothetical conjoint analysis and nonhypothetical experimental auctions. J. Agr. Appl. Econ. 42:757-772.

Yue, C., B. Campbell, C. Hall, B. Behe, J. Dennis, and H. Khachatryan. 2016. Consumer preference for sustainable attributes in plants: Attributes from experimental auctions. Agribusiness 32:222-235. 